\title{
Occurrence of Specific Polychlorinated Biphenyls Congeners in an Industrial Zone
}

\author{
Predrag Ilić1 ${ }^{*}$, Tatjana Nišić ${ }^{2}$ Zia Ur Rahman Farooqi ${ }^{3}$ \\ 'PSRI Institute for Protection and Ecology of the Republic of Srpska, \\ Vidovdanska 43, Banja Luka, Republic of Srpska, Bosnia and Herzegovina \\ ${ }^{2}$ City of Banja Luka, Trg Srpskih Vladara 1, Banja Luka, Republic of Srpska, Bosnia and Herzegovina \\ ${ }^{3}$ Institute of Soil and Environmental Sciences, University of Agriculture, Faisalabad-38040, Pakistan
}

Received: 5 February 2020

Accepted: 5 June 2020

\begin{abstract}
The concentrations and composition of Polychlorinated biphenyls (PCBs) were determined in soils in an industrial zone. Total PCB concentrations ( $\sum$ PCB congeners: PCB28, PCB52, PCB101, PCB118, PCB138, PCB153 and PCB180) varied in range from 0.26 to $6722 \mathrm{mg} / \mathrm{kg}$ in soil, with a median of $31.80 \mathrm{mg} / \mathrm{kg}$. These values indicated that the soil is highly polluted. PCB in the subjected area was the result of anthropogenic activities. The principal component analysis showed that the commercial PCB products (PCB101, PCB118, PCB138, PCB153 and PCB180) are the main cause of pollution (PC1 factor), with $79.38 \%$ of total variance. The $\mathrm{PC} 2$ factor is in relation with the combustion (residential heating and fire in location), with $17.65 \%$ of total variance (lighter chlorinated congeners PCB52 and PCB28). Hierarchical cluster analysis indicated that the PCB congeners in the similar group might have similar sources, which was also confirmed by PCA.
\end{abstract}

Keywords: soils, PCB, congeners

\section{Introduction}

During the preliminary investigations at the subjected site, Polychlorinated biphenyls (PCBs) concentrations was tested [1]. Due to a high contamination with $\mathrm{PCB}$, research has now continued and determination of $\mathrm{PCB}$ concentrations in multiple locations.

PCBs are a group synthetic persistent organic pollutants (POPs) that are widespread, toxic, and ubiquitous in the environment [2-10]. These are industrial chemicals [11], first produced commercially

*e-mail: predrag.ilic@institutzei.net in 1930 [12] and later, widely used in electrical industries [13]. Their presence is always associated with anthropogenic sources. The main sources of PCBs in the environment can be the production of PCBs in industries, industrial products containing PCBs, utilization of PCBs, emission from reservoirs polluted by $\mathrm{PCBs}$ and thermal processes [14].

PCBs include 209 different congeners [5]. Seven PCBs are used as indicator to characterize the presence of PCB contamination. Six of these seven are the non-dioxin-like polychlorinated biphenyls (NDLPCBs) (PCB28 (2,4,4'-trichlorobiphenyl), PCB52 (2,2',5,5'-tetrachlorobiphenyl), PCB101 (2,2',4,5,5'-Pentachlorobiphenyl), PCB138 (2,2',3,4,4',5'-Hexachlorobiphenyl),
PCB153 
(2,2',4,4',5,5'-Hexachlorobiphenyl) and PCB180 (2,2',3,4,4',5,5'-Heptachlorobiphenyl)), and one is a dioxin-like PCBs DL-PCB (PCB118 (2,3',4,4',5-Pentachlorobiphenyl)) [5].

Soils are usually the source and receptor of environmental pollutants [15]. PCBs are, therefore, strongly retained in soils and sediments and important sources of PCB emissions [14]. Soils have acted as an important repository or pool of the PCBs $[16,5]$. The majority of PCBs are derived from industrial sources, hence their concentrations in the environment are usually higher in the areas of higher industrialization and population [3].

This research was aimed to a) measure the concentrations of PCB in soil, b) presentation and discussion of the data related to contamination of soils by PCB and, c) estimate their probable sources in an industrial complex Incel, Banja Luka, Republic of Srpska, Bosnia and Herzegovina. To investigate the difference of congener patterns in soil, correlation analysis, principal component analysis and cluster analysis for PCB congeners (PCA) were used. Patterns of PCB congeners were compared between different sampling sites in an attempt to define similarities between congeners and to estimate emission sources.

\section{Material and Methods}

\section{Study Area}

The subject of the research was to determine the soil pollution (PCB contamination) on the locality Incel (former industrial complex Incel Banja Luka Cellulose Factory in the city of Banja Luka, which is at $3 \mathrm{~km}$ distance from the city center. Banja Luka is the second biggest city in Bosnia and Herzegovina with the population of 185,000 . City is situated in a basin $164 \mathrm{~m}$ above sea level. The average annual temperature reaches $10.7^{\circ} \mathrm{C}$. Location is categorized as a hotspot (waste from cellulose and viscose factory) [17, 18]. Incel is a former company based in Banja Luka, originally manufacturing cellulose, viscose and paper products. During the war of 1991-1995. Incel factory was heavily damaged which resulted in the emission of various toxic substances into the neighboring environment [1].

\section{Sampling and Analysis}

Total 37 soil sites were selected $(0-20 \mathrm{~cm})$ and extensive sampling was performed during October 2019. The selected sites description is as under:

1. Batteries and e-waste recycling site (12 samples).

2. Hazardous waste collection, storage and destruction site (5 samples).

3. Hazardous waste collection and storage site (7 samples).

4. Illegal disposal of hazardous waste (oils, fats, etc.) site (6 samples).
5. Discharge of PCBs (oils from transformer stations) and fire site (7 samples).

Chemical analyses were conducted on the soil samples, including $\sum \mathrm{PCB}$ and $\mathrm{PCB}$ congeners: $\mathrm{PCB} 28$, PCB52, PCB101, PCB138, PCB153 and PCB180. PCB analysis was performed in laboratory which is accredited with ISO 17025 standard for PCB measurements by Gas chromatography, based on the principles described in Standard Methods with disintegration techniques and analyzed and according with national legislation [19] and standards described by ISO 22892:2006, EPA 8082A:2007 and EPA 3546:2007.

\section{Statistical Analysis}

A significance level of $p$ value $p<0.01$ and $p<0.001$ was used. Descriptive statistical operations were applied for the analysis of the collected data. Correlation (Spearman's, Pearson's and Kendall test), factor analysis (principal component analysis) and cluster analysis were applied for getting the qualitative information about the possible source of the five kinds of $\sum \mathrm{PCB}$ and $\mathrm{PCB}$ congeners. Excel 2016, JASP 0.8.5.1 softwares were used for statistical data processing.

\section{Results and Discussion}

Total PCB concentrations ( $\sum \mathrm{PCB}$ congeners: PCB28, PCB52, PCB101, PCB118, PCB138, PCB153 and $\mathrm{PCB} 180$ ) varied in range from 0.26 to $6722 \mathrm{mg} / \mathrm{kg}$ in soil, with a median of $31.80 \mathrm{mg} / \mathrm{kg}$ (Table 1 and Fig. 1). Significant variation in PCB concentrations in the soils between different sites could partly be explained by nearness to the sources; another factor, i.e. wind direction may also play a major role in it. PCB52 congeners were found with the highest mean concentration of $(9.005 \mathrm{mg} / \mathrm{kg})$, followed by PCB28, PCB101, PCB118, PCB138, PCB180 and PCB153, whose mean concentrations were 13.59, 33.87, 57.34, 97.31, 135.80 and $148.40 \mathrm{mg} / \mathrm{kg}$, respectively. Previous studies indicate that level of PCBs on several sampling sites in this locality was as high as $400 \mathrm{mg} / \mathrm{kg}$ and of the dry soil sample, which are two folds higher than on any other investigated site performed by UMASA. RECETOX [20] and $600 \mathrm{mg} / \mathrm{kg}$ [1]. According to the national standards, all the concentrations of $\sum \mathrm{PCB}$ congeners found in this study were significantly higher than the permissible value of $0.2 \mathrm{mg} / \mathrm{kg}$ in agricultural soils [19]. The median concentration of PCB congeners was higher than the concentration in industrial sites in China [13].

Using Kruskal-Wallis test for equal medians, it was shown that significant differences were found among these PCB congeners medians $\left(\mathrm{H}\left(\mathrm{chi}^{2}\right)=32.92\right.$, Hc (tie corrected $)=32.92, \mathrm{p}($ same $)=2.736 \mathrm{E}-05)$.

Skewness test values greater or lesser than 1.96 are sufficient to establish normality of the data (for all congeners) [21]. Skewness and Kurtosis test for all 
Table 1. Statistical summary of total PCB and PCB congeners (PCB28, PCB52, PCB101, PCB118, PCB138, PCB153 and PCB180).

\begin{tabular}{|c|c|c|c|c|c|c|c|c|}
\hline & PCB total & PCB28 & PCB52 & PCB101 & PCB118 & PCB138 & PCB153 & PCB180 \\
\hline Valid & 37 & 37 & 37 & 37 & 37 & 37 & 37 & 37 \\
\hline Mean & 495.4 & 13.59 & 9.005 & 33.87 & 57.34 & 97.31 & 148.4 & 135.8 \\
\hline Median & 31.80 & 0.6500 & 1.520 & 1.470 & 1.670 & 2.770 & 3.250 & 2.440 \\
\hline Std. Deviation & 1238 & 31.12 & 14.83 & 83.92 & 140.5 & 236.1 & 375.4 & 420.8 \\
\hline Coefficient of Variation & 249.95 & 228.91 & 164.70 & 247.74 & 245.09 & 242.63 & 252.91 & 309.78 \\
\hline Variance & $1.533 \mathrm{e}+6$ & 968.4 & 220.0 & 7042 & $1.975 \mathrm{e}+4$ & $5.575 \mathrm{e}+4$ & $1.409 \mathrm{e}+5$ & $1.771 \mathrm{e}+5$ \\
\hline Skewness & 3.952 & 2.945 & 2.193 & 3.677 & 3.455 & 3.371 & 3.554 & 4.632 \\
\hline Kurtosis & 18.14 & 8.453 & 4.833 & 15.08 & 13.29 & 12.87 & 14.44 & 23.82 \\
\hline Range & 6722 & 139.8 & 61.64 & 434.7 & 709.3 & 1190 & 1933 & 2385 \\
\hline Minimum & 0.26 & 0.01 & 0.01 & 0.01 & 0.02 & 0.04 & 0.03 & 0.01 \\
\hline Maximum & 6722 & 139.8 & 61.65 & 434.7 & 709.3 & 1190 & 1933 & 2385 \\
\hline
\end{tabular}

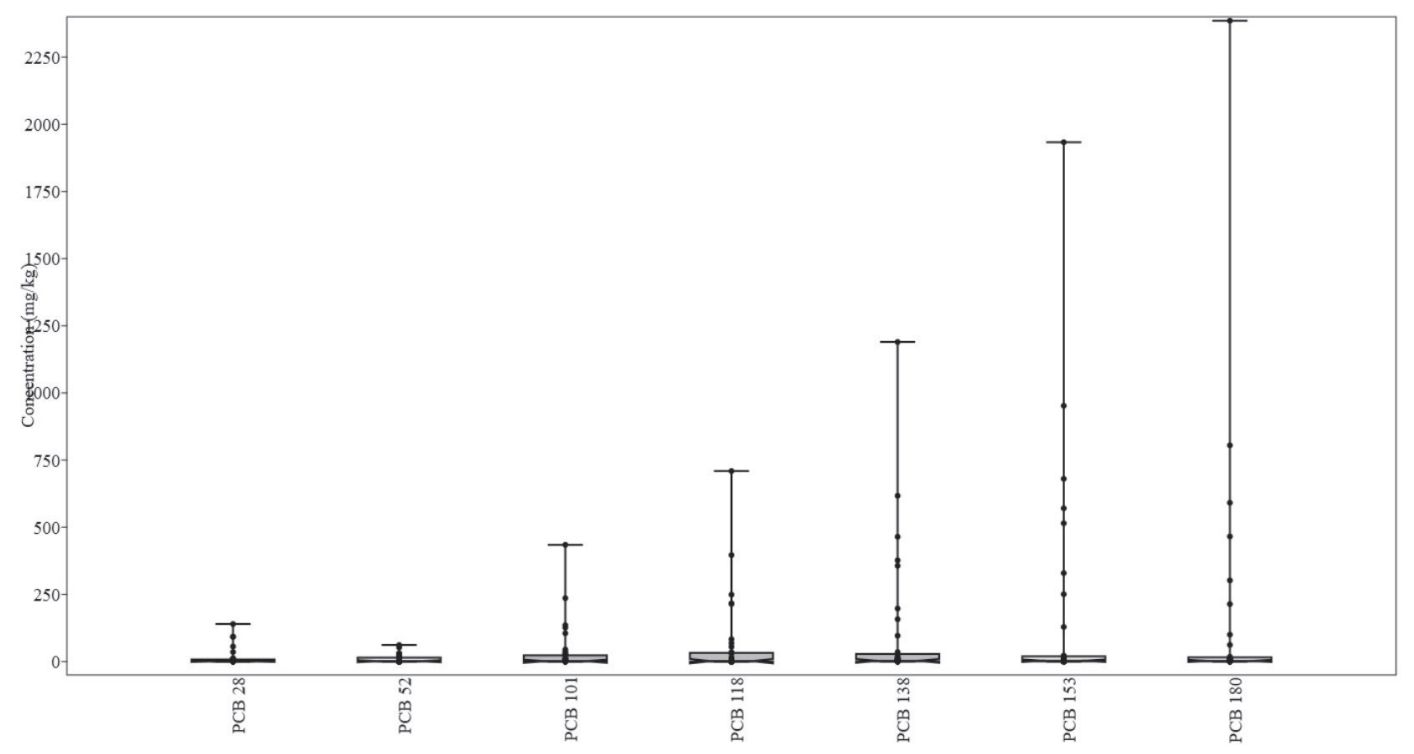

Fig. 1. Box and jitter plot.

congeners shown that data distribution is not normal. Coefficient of variation (CV) (as an index variability), indicates high anthropogenic contribution $(>0.90)$ [21].

Fig. 2 is showing high variation $\mathrm{PCB}$ congeners in all sites. Frequency of PCB congeners in soil in five location (median values) is shown in Fig. 3. The highest total PCB mass fraction was found in Location 5 (central areas of industrial zone) (Discharge of PCBs and fire site) $(1754 \mathrm{mg} / \mathrm{kg})$. In location 1, high concentrations of chlorinated congeners (PCB138, PCB153 and PCB180) were found which was due to nearness of batteries and e-waste recycling facilities. PCBs in electrical equipment are potentially the greatest source of environmental pollution by PCBs and they are considered as a priority source of environment pollution by PCBs [14], which were also confirmed by the results of this study. Electronic waste (e-waste) recycling facilities were adding higher PCB concentrations in soil [23]. Thus, the investigation of Leung et al (2006) and Tu et al. (2017) [24, 5], showed that soil may be polluted with PCBs due to the improper handling and recycling of electronic waste (e-waste) and storage of old capacitor equipment. In location 3, highly hydrophobic PCB28 (lighter chlorinated congener) were in higher concentrations which was hazardous waste collection and storage site, indicating that the site is not the primary source of pollution in the Incel area, but secondary. Contamination was due to secondary collection and disposal of site waste and atmospheric transport from other locations. As shown in Fig. 3, Hexa-chlorinated PCB138 and PCB180 (Highly chlorinated congeners) had high median concentration in Location 4 (due to illegal disposal of hazardous waste i.e.oils, fats, etc.)). Similar values were obtained 


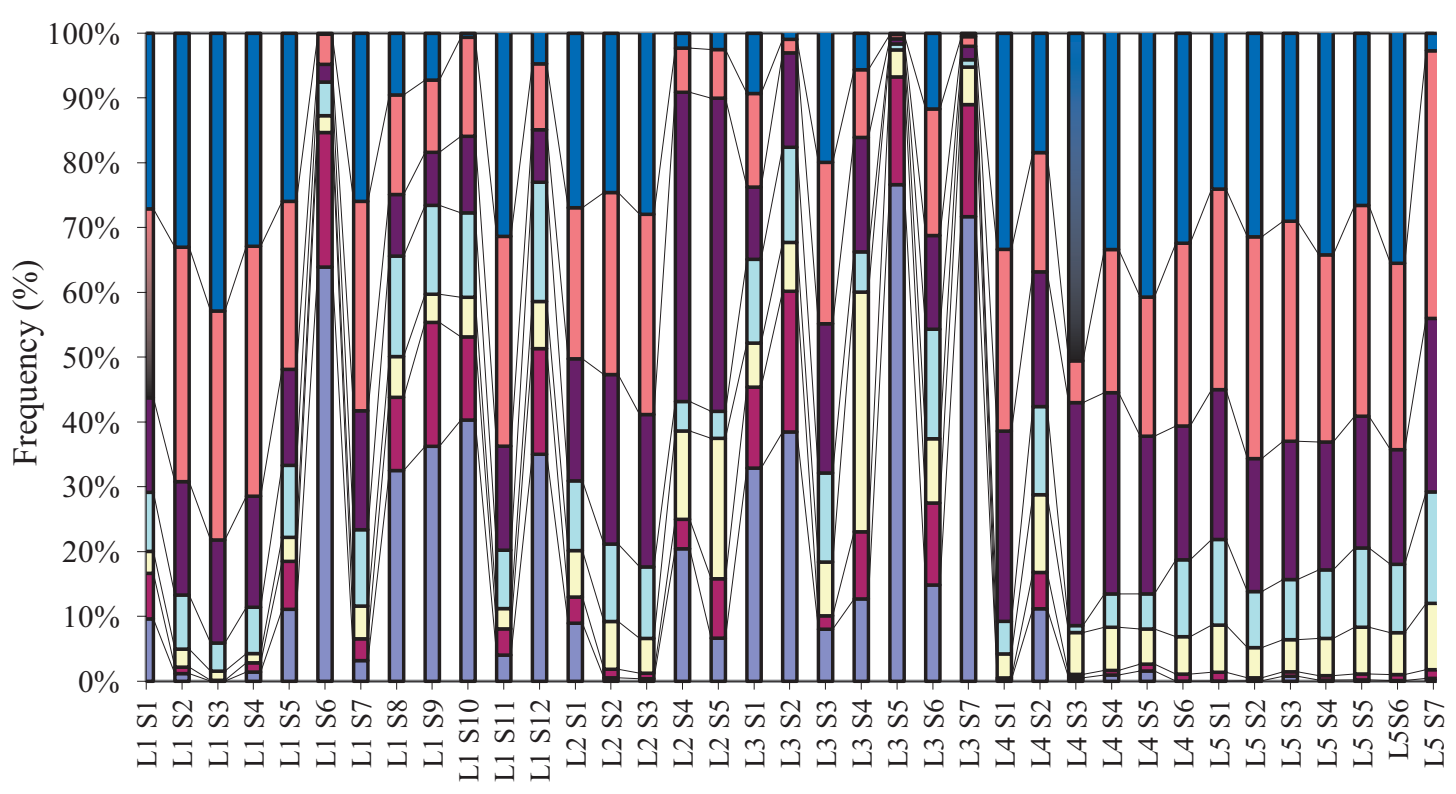

$\begin{array}{lllllll}\text { 口PCB } 28 & \text { 口PCB } 52 & \text { 口PCB } 101 & \text { 口PCB } 118 & \text { 口PCB } 138 & \text { 口PCB } 153 & \text { 口PCB } 180\end{array}$

Fig. 2. Frequency of PCB congeners in soil in five location (35 samples).

at Location 2 (due to hazardous waste collection, storage and destruction). Values of PCB in Location 5 (with higher median values $\sum$ PCB) is co-related to discharge of PCBs (oils from transformer stations) and fire. In location 5 PCB153 had high median value. PCB153 is highly chlorinated congeners and high highly congeners of PCBs in location 4 might be associated with discharge and burning of electric cables from transformers. Highly chlorinated PCBs congeners tend to remain closer to their source regions [25], as confirmed by the results of this study. PCB118 As shown in Fig. 2 and 3, PCB118, a mono-ortho congener and the most abundant congener in location 5, has the highest potential toxicity among the 13 congeners, with its toxic equivalency factors as 0.0001 recommended by the WHO [15].

The correlation analysis for total PCB and PCB congeners are shown in Table 2. The results of the correlation analysis for indicators (congeners) is positive for the level of significance $\mathrm{p}<0.001$ (Pearson's and

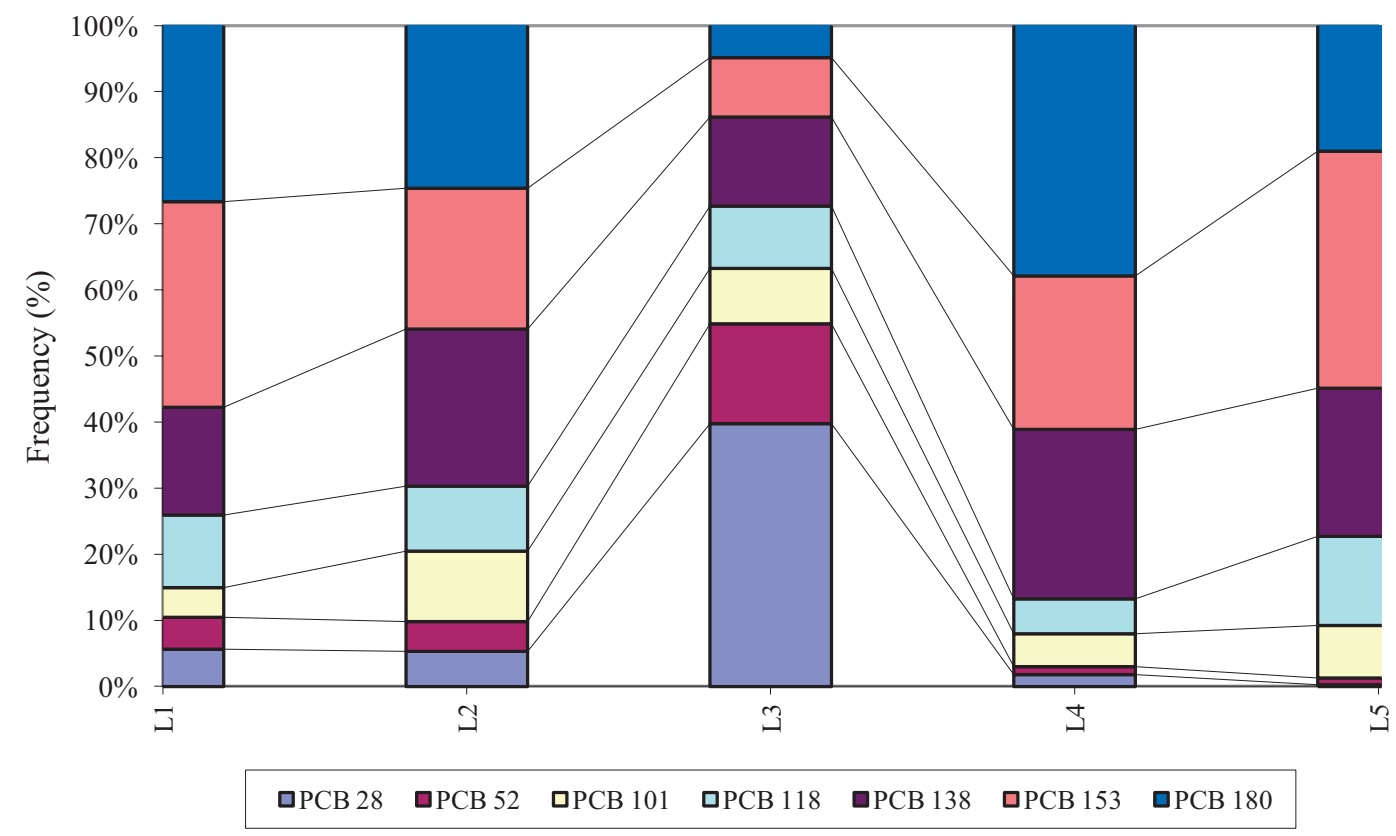

Fig. 3. Frequency of PCB congeners in soil in five location. 
Table 2. Correlation between PCB congeners.

\begin{tabular}{|c|c|c|c|c|c|c|}
\hline & \multicolumn{2}{|c|}{ Pearson } & \multicolumn{2}{|c|}{ Spearman } & \multicolumn{2}{|c|}{ Kendall } \\
\hline & $\mathrm{r}$ & $\mathrm{p}$ & rho & $\mathrm{p}$ & tau B & $\mathrm{p}$ \\
\hline$\sum$ PCB-PCB28 & -0.051 & 0.764 & $0.681 * * *$ & $<0.001$ & $0.480 * * *$ & $<0.001$ \\
\hline$\sum$ PCB-PCB52 & $0.697 * * *$ & $<0.001$ & $0.873 * * *$ & $<0.001$ & $0.683 * * *$ & $<0.001$ \\
\hline$\sum$ PCB-PCB101 & $0.982 * * *$ & $<0.001$ & $0.971 * * *$ & $<0.001$ & $0.877 * * *$ & $<0.001$ \\
\hline$\sum$ PCB-PCB118 & $0.984 * * *$ & $<0.001$ & $0.966 * * *$ & $<0.001$ & $0.881 * * *$ & $<0.001$ \\
\hline$\sum$ PCB-PCB138 & $0.989 * * *$ & $<0.001$ & $0.940 * * *$ & $<0.001$ & $0.831 * * *$ & $<0.001$ \\
\hline$\sum$ PCB-PCB153 & $0.991 * * *$ & $<0.001$ & $0.919 * * *$ & $<0.001$ & $0.808 * * *$ & $<0.001$ \\
\hline$\sum$ PCB-PCB180 & $0.959 * * *$ & $<0.001$ & $0.836 * * *$ & $<0.001$ & $0.694 * * *$ & $<0.001$ \\
\hline РCB28-PCB52 & $0.591 * * *$ & $<0.001$ & $0.904 * * *$ & $<0.001$ & $0.746 * * *$ & $<0.001$ \\
\hline PCB28-PCB101 & -0.051 & 0.765 & $0.675 * * *$ & $<0.001$ & $0.477 * * *$ & $<0.001$ \\
\hline PCB28-PCB118 & -0.064 & 0.705 & $0.661 * * *$ & $<0.001$ & $0.457 * * *$ & $<0.001$ \\
\hline PCB28-PCB138 & -0.085 & 0.616 & $0.509 * *$ & 0.001 & $0.328 * *$ & 0.004 \\
\hline PCB28-PCB153 & -0.092 & 0.589 & $0.481 * *$ & 0.003 & $0.314 * *$ & 0.006 \\
\hline PCB28-PCB180 & -0.083 & 0.623 & 0.296 & 0.075 & 0.177 & 0.126 \\
\hline PCB52-PCB101 & $0.707 * * *$ & $<0.001$ & $0.874 * * *$ & $<0.001$ & $0.686 * * *$ & $<0.001$ \\
\hline PCB52-PCB118 & $0.702 * * *$ & $<0.001$ & $0.851 * * *$ & $<0.001$ & $0.663 * * *$ & $<0.001$ \\
\hline PCB52-PCB138 & $0.678 * * *$ & $<0.001$ & $0.739 * * *$ & $<0.001$ & $0.543 * * *$ & $<0.001$ \\
\hline PCB52-PCB153 & $0.669 * * *$ & $<0.001$ & $0.697 * * *$ & $<0.001$ & $0.514 * * *$ & $<0.001$ \\
\hline PCB52-PCB180 & $0.621 * * *$ & $<0.001$ & $0.538 * * *$ & $<0.001$ & $0.384 * * *$ & $<0.001$ \\
\hline PCB101-PCB118 & $0.997 * * *$ & $<0.001$ & $0.959 * * *$ & $<0.001$ & $0.843 * * *$ & $<0.001$ \\
\hline PCB101-PCB138 & $0.992 * * *$ & $<0.001$ & $0.945 * * *$ & $<0.001$ & $0.825 * * *$ & $<0.001$ \\
\hline PCB101-PCB153 & $0.993 * * *$ & $<0.001$ & $0.900 * * *$ & $<0.001$ & $0.763 * * *$ & $<0.001$ \\
\hline PCB101-PCB180 & $0.894 * * *$ & $<0.001$ & $0.814 * * *$ & $<0.001$ & $0.643 * * *$ & $<0.001$ \\
\hline PCB118-PCB138 & $0.997 * * *$ & $<0.001$ & $0.949 * * *$ & $<0.001$ & $0.838 * * *$ & $<0.001$ \\
\hline PCB118-PCB153 & $0.995 * * *$ & $<0.001$ & $0.957 * * *$ & $<0.001$ & $0.848 * * *$ & $<0.001$ \\
\hline PCB118-PCB180 & $0.894 * * *$ & $<0.001$ & $0.872 * * *$ & $<0.001$ & $0.710 * * *$ & $<0.001$ \\
\hline PCB138-PCB153 & $0.998 * * *$ & $<0.001$ & $0.962 * * *$ & $<0.001$ & $0.855 * * *$ & $<0.001$ \\
\hline PCB138-PCB180 & $0.910 * * *$ & $<0.001$ & $0.932 * * *$ & $<0.001$ & $0.794 * * *$ & $<0.001$ \\
\hline PCB153-PCB180 & $0.916 * * *$ & $<0.001$ & $0.966 * * *$ & $<0.001$ & $0.853 * * *$ & $<0.001$ \\
\hline
\end{tabular}

$* * \mathrm{p}<0.01, * * * \mathrm{p}<0.001$

Spearman's Correlation Coefficient test), except for PCB28 correlation with congeners PCB101, PCB118, PCB138, PCB153 and PCB180.

Correlation between $\sum$ PCB with PCB101, PCB118, PCB138, PCB153, PCB180; PCB101 with PCB118, PCB138, PCB153, PCB180; PCB118 with PCB138, PCB153, PCB180; PCB138 with PCB153 and PCB180; $\mathrm{PCB} 153$ and $\mathrm{PCB} 180$ is a strong positive correlation, which means that high $\mathrm{X}$ variable ( $\mathrm{PCB}$; PCB101; PCB118; PCB138; PCB153) scores go with high Y variable scores (PCB101, PCB118, PCB138, PCB153, PCB180; PCB118, PCB138, PCB153, PCB180; PCB138,
PCB153, PCB180; PCB153 and PCB180; PCB180) (and vice versa). The value of $\mathrm{R}$ is $0.9823,0.9835,0.989$, $0.9909,0.9585,0.9966,0.9923,0.9935,0.8942,0.997$, $0.9955,0.894,0.9985,0.9099$ and 0.9163 , respectively. The value of R2, the coefficient of determination, is $0.9649,0.9673,0.9781,0.9819,0.9187,0.9932,0.9847$, $0.987,0.7996,0.994,0.991,0.7992,0.997,0.8279$ and 0.8396 , respectively.

Correlation of $\sum \mathrm{PCB}$ with $\mathrm{PCB} 53$; $\mathrm{PCB} 28$ with PCB52; PCB52 with PCB101, PCB118, PCB138, PCB153 and $\mathrm{PCB} 180$ is a moderate positive correlation which means there is a tendency for high $\mathrm{X}$ variable scores 
Table 3. Component loading for PCB congeners and eigenvalue and percentage variance for factors.

\begin{tabular}{|c|c|c|c|}
\hline & PC 1 & PC 2 & Uniqueness \\
\hline PCB101 & 0.989 & 0.086 & 0.014 \\
\hline PCB118 & 0.991 & 0.074 & 0.011 \\
\hline PCB138 & 0.995 &. & 0.008 \\
\hline PCB153 & 0.996 &. & 0.007 \\
\hline PCB180 & 0.935 &. & 0.125 \\
\hline PCB28 & -0.137 & 0.979 & 0.022 \\
\hline PCB52 & 0.654 & 0.727 & 0.044 \\
\hline Eigenvalue & 6.35049 & 1.41221 & \\
\hline Variance (\%) & 79.381 & 17.653 & \\
\hline Total variance (Cum \%) & 79.381 & 97.034 & \\
\hline & & &
\end{tabular}

go with high $\mathrm{Y}$ variables scores (and vice versa). The values of $\mathrm{R}$ are $0.6973,0.5914,0.707,0.702,0.678,0.669$ and 0.621 , respectively. The value of $\mathrm{R} 2$, the coefficient of determination, are 0.4862, 0.3498, 0.4998, 0.4925, $0.4598,0.447$ and 0.3851 , respectively.

Correlation of $\sum$ PCB with PCB28; PCB28 with PCB101, PCB118, PCB138, PCB153 and PCB180 is technically a negative correlation, the relationship between variables is only weak. The value of $\mathrm{R}$ are $-0.051,-0.0509,-0.0643,-0.0852,-0.0919$ and -0.0835 , respectively. The value of $\mathrm{R} 2$, the coefficient of determination, are 0.0026, 0.0026, 0.0041, 0.0073, 0.0084 and 0.007 , respectively.

So, the results confirm the Spearman and Kurtosis test that variables are not normally distributed and more important is the Spearman rank correlation method. Such results suggest that these PCB congeners pairs might have similar sources or have been affected by similar factors.

To investigate the difference of congener patterns in soil, factor analysis (FA) was applied, i.e. principal component analysis (PCA). The primary output for a PCA shows the correlation between each variable (PCB congeners) of a principal component and the variable factors (PC1 and PC2) (Table 3).

PCA creates one or more index variables (components) from a set of measured variables. In this study (Table 3, Fig. 4a), 97.73\% of the variability in seven variables (PCB congeners) was explained by two components, $\mathrm{PC} 1$ and $\mathrm{PC} 2$. The relationships among indicators (congeners) are displayed in the score plot (Fig. 2a). From the direction of the arrows that the variables (PCB congeners) contribute to the variable factors. The weights to emphasize PCB101, PCB118, PCB138, PCB153 and PCB180 (for PC1), and PCB28 and $\mathrm{PCB} 52$ (for $\mathrm{PC} 2$ ) variables more than others.

Using PCA we obtained two factors that clarify the grouping of pollutants: factor $\mathrm{PC} 1$ represents the highly chlorinated biphenyls (PCB118, PCB138, PCB153 and a)

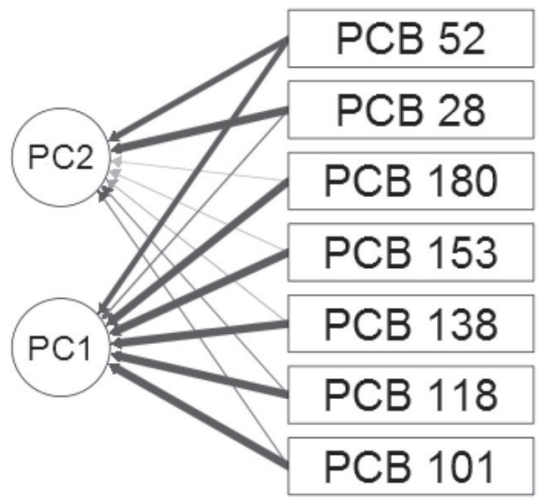

b)

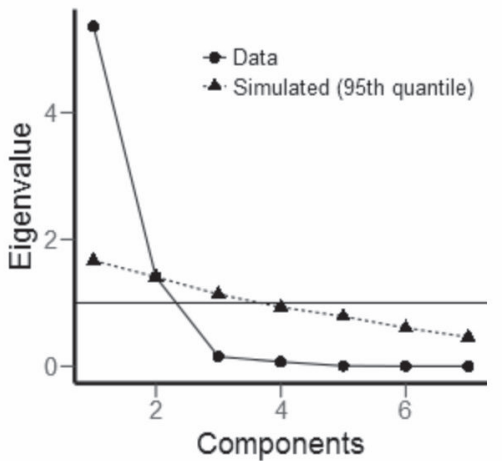

Fig. 4. Path diagram(a) and scree plot b).

PCB180) and one the lighter congeners (PCB101), factor PC2 represents the lighter congeners like PCB28 and PCB52. Highly chlorinated congeners, due to its properties, tend to remain closer to their sources [25]. Lighter chlorinated congeners show higher volatility and higher potential for long-range atmospheric transport compared with higher chlorinated PCBs congeners [26].

The PC1 factor was primarily associated with highly chlorinated biphenyls (PCB101, PCB118, PCB138, PCB153 and PCB180) in general, and explained 79.38\% of total variance. All PCB congeners were strong and positively loaded ( $>0.75$ ) [27] (Table 3). These compounds are the main components of technical PCB mixtures [28] and their presence in soils indicate commercial PCB products as their source in soil [26].

The PC2 factor is in relation with the combustion. In coal and hardwood combustion emissions are dominated by PCB52 and PCB28 [29]. This factor was attributed to coal and wood combustion (residential heating). This factor explained $17.65 \%$ of total variance. PCB28 was strong and positively loaded $(>0.75)$. PCB52 was moderate loaded (0.75-0.50) (Table 3) [27]. PCB28 and PCB52 in soil to be higher half-life 10.9 and 11.2 years, respectively [15], as lighter congener might be reflecting fresh inputs [23] and be due to atmospheric transport from the emission from other location.

Fig. 4b) is showing PCA scree plot. Eigen values higher than one were taken as criterion for evaluating the principal components required to explain the sources of variance in the data. According to varimax 


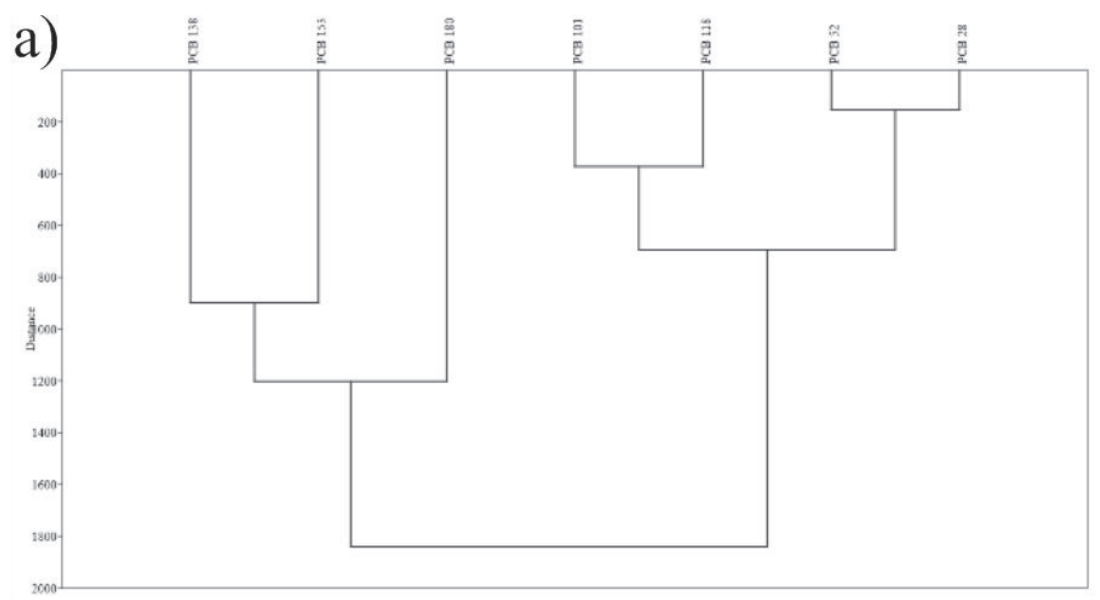

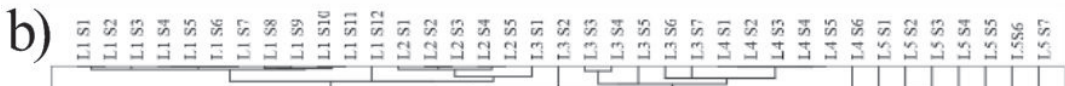

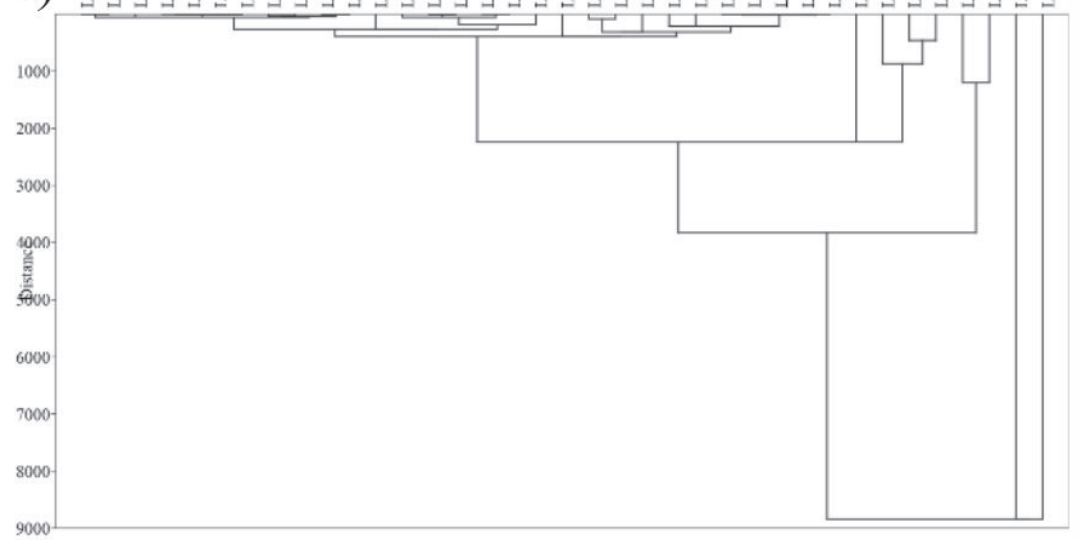

Fig. 5. Results of cluster analysis for a) PCB congeners and b) locations.

the rotation method, two factors explained $97.73 \%$ of the total variance.

The hierarchical cluster analysis (CA) for PCB congeners was applied to the data, and the Paired group (UPGMA) methods distance chosen for calculation. CA was performed to check the results of the PC analysis. The results of the CA yield a slightly similar result like PCA. From results, two main groups were identified. PCB28 and PCB52 and PCB101 and PCB118 (Group 1) and other PCB congeners (PCB138, PCB153 and PCB 160) (Group 2), which indicated that the PCB congeners in the similar group might have similar sources (Fig. 5a), which was also confirmed by PCA.

The results of the CA per location confirmed results like PCA. From the results, two five groups were identified. Basically, five locations confirm five group 1), which indicated that the PCB congeners in location have similar sources (Fig. 5b), which was also confirmed by PCA.

\section{Conclusions}

Results from the study confirmed the soil contamination by polychlorinated biphenyl (PCB) oils from transformer stations in the vicinity of the Factory.
Total PCB concentrations ( $\sum \mathrm{PCB}$ congeners: PCB28, PCB52, PCB101, PCB118, PCB138, PCB153 and $\mathrm{PCB} 180$ ) varied in range from 0.26 to $6722 \mathrm{mg} / \mathrm{kg}$ in soil, with a median of $31.80 \mathrm{mg} / \mathrm{kg}$. According to the national standards, the concentrations of $\left(\sum \mathrm{PCB}\right.$ congeners: PCB28, PCB52, PCB101, PCB118, PCB138, $\mathrm{PCB} 153$ and $\mathrm{PCB} 180$ ) found significantly higher than their maximum admissible value of $0.2 \mathrm{mg} / \mathrm{kg}$.

Principal component analysis shown that commercial PCB products and highly chlorinated biphenyls (PCB101, PCB118, PCB138, PCB153 and $\mathrm{PCB} 180)$ are the main cause of soil pollution ( $\mathrm{PC} 1$ factor), with $79.38 \%$ of total variance. The $\mathrm{PC} 2$ factor is in relation with the combustion. In coal and hardwood, combustion emissions are dominated by lighter chlorinated congeners by PCB52 and PCB28. This factor was attributed to coal and wood combustion (residential heating), with $17.65 \%$ of total variance.

From the results of hierarchical cluster analysis, two main groups of PCBs were identified i.e.PCB28 and PCB52 and PCB101 and PCB118 (Group 1) and other PCB congeners (PCB138, PCB153 and PCB 160) (Group 2), which indicated that the $\mathrm{PCB}$ congeners in the similar group might have similar sources, which was also confirmed by PCA. The results of the CA per location confirm result like PCA. 
The frequency of PCB congeners in soil in five locations (median values) indicated that values of total PCB ( $\Sigma$ PCB) and PCB congeners in soils in location depends on the activity at the site (e-waste recycling, hazardous waste collection, illegal disposal of hazardous waste or discharge of PCBs and fire).

Furthermore, results of this study reflects the effects of uncontrolled industrial and storage activities at the subjected site. This is the first study on levels of PCB congeners in industrial soils in Banja Luka and provides baseline information for further studies and additional investigation about this industrial zone. Near industrial zone need to determine the risk level in this area, it is necessary to investigate the exposure of food and people to PCBs.

\section{Acknowledgements}

The present study was conducted using equipment from the PSRI Institute for Protection and Ecology of the Republic of Srpska, Banja Luka. This research was done in the frame of project "Environmental assessment correlated with the environmental risks in the urban area", granted by the Ministry for Scientific and Technological Development, Higher Education and Information Society of Republic of Srpska (19/6020/961-96/18)

\section{Conflict of Interest}

The authors declare no conflict of interest.

\section{References}

1. ILIĆ P., NIŠIĆ T., ILIĆ S., STOJANOVIĆ BJELIĆ L.J. The identification of new 'hotspot' of heavy metal contamination of soil in industrial zone. Pol. J. Environ. Stud. 29 (4), 2987, 2020.

2. CHOI J.Y., YANG D.B., HONG G.H., KIM K., SHIN K.H. Ecological and human health risk from polychlorinated biphenyls and organochlorine pesticides in bivalves of Cheonsu Bay, Korea. Environmental Engineering Research. 21 (4), 373, 2016.

3. MALISZEWSKA-KORDYBACH B., SMRECZAK B., KLIMKOWICZ-PAWLAS A. The levels and composition of persistent organic pollutants in alluvial agriculture soils affected by flooding. Environmental monitoring and assessment. 185 (12), 9935, 2013.

4. DUMANOGLU Y., GAGA E.O., GUNGORMUS E., SOFUOGLU S.C., ODABASI M. Spatial and seasonal variations, sources, air-soil exchange, and carcinogenic risk assessment for PAHs and PCBs in air and soil of Kutahya, Turkey, the province of thermal power plants. Science of the Total Environment. 580, 920, 2017.

5. TU C., MA L., GUO P., SONG F., TENG Y., ZHANG H., LUO Y. Rhizoremediation of a dioxin-like PCB polluted soil by alfalfa: Dynamic characterization at temporal and spatial scale. Chemosphere. 189, 517, 2017.
6. KIM A.W., VANE C.H., MOSS-HAYES V.L., BERIRO D.J., NATHANAIL C.P., FORDYCE F.M., EVERETT P.A. Polycyclic aromatic hydrocarbons (PAHs) and polychlorinated biphenyls (PCBs) in urban soils of Glasgow, UK. Earth Environ. Sci. Trans. R. Soc. Edinb. 108 (2-3), 231, 2018.

7. VANE C.H., KIM A.W., BERIRO D.J., CAVE M. R., KNIGHTS K., MOSS-HAYES V., NATHANAIL P.C. Polycyclic aromatic hydrocarbons (PAH) and polychlorinated biphenyls (PCB) in urban soils of Greater London, UK. Applied Geochemistry. 5, 303, 2014.

8. OMAR W.A., MAHMOUD H.M. Risk assessment of polychlorinated biphenyls (PCBs) and trace metals in River Nile up-and downstream of a densely populated area. Environ.Geochem. Health. 39 (1), 125, 2017.

9. AGANBI E., IWEGBUE C.M., MARTINCIGH B.S. Concentrations and risks of polychlorinated biphenyls (PCBs) in transformer oils and the environment of a power plant in the Niger Delta, Nigeria. Toxicology reports. 6, 933, 2019.

10. ŠKRBIĆ B.D., ANTIĆ I., YAQIN J. Levels and risk assessment of selected persistent organic compounds in dust samples from Tianjin, China. Acta Periodica Technologica. 50, 295, 2019.

11. DVORŠĆAK M., STIPIČEVIĆ S., MENDAŠ G., DREVENKAR V., MEDUNIĆ G., STANČIĆ Z., VUJEVIĆ D. Soil burden by persistent organochlorine compounds in the vicinity of a coal-fired power plant in Croatia: a comparison study with an urban-industrialized area. Environmental Science and Pollution Research. 1, 2019.

12. World Health Organization. Safety evaluation of certain food additives and contaminants, Supplement 1: Nondioxin-like polychlorinated biphenyls. WHO food additives series: 71-S1 Joint FAO/WHO Expert Committee on Food Additives (JECFA), 2016.

13. HUANG J., AMUZU-SEFORDZI B., LI M. Heavy metals and polychlorinated biphenyls (PCBs) sedimentation in the Lianhua Mountain Reservoir, Pearl River Delta, China. Environmental monitoring and assessment. 187 (5), 254 (1-12), 2015.

14. KAKAREKA S., KUKHARCHYK T. Sources of poychlorinated biphenyls emissions EMEP/CORINAIR Guidebook, 2005.

15. ZHANG J.Y., QIU L.M., JIA H.E., YUAN L., LUO Y.M. Occurrence and congeners specific of polychlorinated biphenyls in agricultural soils from Southern Jiangsu, China. Journal of environmental sciences. 19 (3), 338, 2007.

16. BACKE C., COUSINS I.T., LARSSON P. PCB in soils and estimated soil-air exchange fluxes of selected PCB congeners in the south of Sweden. Environmental Pollution. 128 (1-2), 59, 2004.

17. JICA expert team (NIPPON KOEI CO., LTD.). The project for master plan for remediation of hotspots in Bosnia and Herzegovina. May 2014 Japan international cooperation agency. Ministry of foreign trade and economic relations, Bosnia and Herzegovina and Federal ministry of environment and tourism, Federation of Bosnia and Herzegovina. 2014.

18. National implementation plan for the Stockholm convention in Bosnia and Herzegovina. Global Environment Facility United Nations Industrial Development Organization. Bosnia and Herzegovina Ministry of foreign trade and economic relations. 2015 . 
19. RULEBOOK on allowable quantities of dangerous and hazardous matters in soil and irrigation water and methods for their testing ("Official Gazette of the Republic of Srpska”, No. 56/16), 2016 [In Serbian].

20. Scientific report. [Internet]. 2019. Available from: http:// www.recetox.muni.cz/projekty/apopsbal/sources/final/ scientific-report.pdf. (accessed on 30/12/2019).

21. GHASEMI A., ZAHEDIASL S. Normality tests for statistical analysis: a guide for non-statisticians. International journal of endocrinology and metabolism. 10 (2), 486, 2012.

22. CEPA (Chinese Environmental Protection Administration). Elemental background values of soils in China. Environmental Science Press of China, Beijing, 1990.

23. CHAKRABORTY P., ZHANG G., LI J., SELVARAJ S., BREIVIK K., JONES K.C. Soil concentrations, occurrence, sources and estimation of air-soil exchange of polychlorinated biphenyls in Indian cities. Science of the total environment. 562, 928, 2016.

24. LEUNG A., CAI Z.W., WONG M.H. Environmental contamination from electronic waste recycling at Guiyu, southeast China. J. Mater. Cycles Waste Manag. 8 (1), 21, 2006.

25. WYRZYKOWSKA B., HANARI N., ORLIKOWSKA A., BOCHENTIN I., ROSTKOWSKI P., FALANDYSZ
J., TANIYASU S,. HORII Y., JIANG Q., YAMASHITA N. Polychlorinated biphenyls and naphthalenes in pine needles and soil from Poland-concentrations and patterns in the view of the long-term environmental monitoring. Chemosphere. 67, 1877, 2007.

26. MEIJER S.N., OCKENDEN W.A., SWEETMAN A., BREIVIK K., GRIMALT J.O., JONES K.C. Global distribution and budget of PCBs and HCB in background surface soils: implications for sources and environmental processes. Environ Sci Technol. 37, 667, 2003.

27. LIU C.W., LIN K.H., KUO Y.M. Application of factor analysis in the assessment of groundwater quality in a Blackfoot disease area in Taiwan. Science of the Total Environment. 313 (1-3), 77, 2003.

28. JIN R.H., PARK S.U., PARK J.E., KIM J.G. Polychlorinated biphenyl congeners in river sediments: distribution and source identification using multivariate factor analysis. Arch. Environ. Contam. Toxicol. 62, 411, 2012.

29. LEE R.G.M., COLEMAN P., JONES J.L., JONES K.C., LOHMANN R. Emission factors and importance of PCDD/Fs, PCBs, PCNs, PAHs and PM10 from the domestic burning of coal and wood in the UK. Environ. Sci. Technol. 39, 1436, 2005. 